\title{
LETTER
}

\section{Diagnosis of Hb-pathies}

European Journal of Human Genetics (2002) 10, 672. doi:10.1038/sj.ejhg.5200885

I would like to praise the EJHG and the authors Villard and Fontes ${ }^{1}$ for the concise and practical updating on X-linked alpha thalassaemia/mental retardation syndrome.

I would also like to place an additional remark on the paragraph 'Diagnosis'. The authors state correctly that the $\mathrm{X}$-linked alpha thalassaemia phenotype in affected males can be detected by haemoglobin electrophoresis or by the presence of $\mathrm{HbH}$ inclusion bodies in peripheral blood smears.

However, only the $--/-\alpha$ (HbH disease) and $--/--$ (Hb-Bart's Hydrops Foetalis) genotypes result in an abnormal electrophoresis which is otherwise normal in alpha thalassaemia. Hence, one may expect in X-linked alpha thalassaemia females, but depending on the lack of $\alpha$ expression also in males, that the $\mathrm{HbH}$ fraction could be below detection level on electrophoresis or could have disappeared because of the typical instability of this nonfunctional tetramer.

The same can happen looking at the $\mathrm{HbH}$ inclusion bodies in the peripheral blood. Moreover, this test is working well in skilled hands but may easily produce false positive or false negative interpretations in most (inexperienced) labs.

Probably because of the concise character of their publication the authors did not mention the parameters that may give the most reliable diagnostic indications, which are: (1) The simple observation of the haematological indices (thalassaemic patients are microcytic and hypochromic without iron deficiency); and (2) The measurement of the $\beta / \alpha$ expression rate at the mRNA or at the protein level (globine chains synthesis), which is always unbalanced in thalassaemias, globin gene related or not.

PC Giordano Hemoglobinopathies and red cell diagnostics, Human and Clinical Genetics, Leiden University Medical Center, The Netherlands,

E-mail: p.c.giordano@lumc.nl

\section{Reference}

1 Villard L, Fontes M: Diagnosis of Hb-pathies. Eur J Hum Genet 2002; 10: $223-225$. 